\title{
In-vitro Comparison of Antibacterial (Triclosan) Coated Suture Material with Non-coated Suture Material against common Bacterial pathogens Causing Surgical Site Infection
}

\author{
S. Soumya*, Praful S. Maste and Sumati Hogade \\ Department of Microbiology and Department of Neurosurgery, Jawaharlal Nehru Medical \\ College, KLES Dr. Prabhakar Kore Hospital and Medical Research Center, KLE University, \\ Belgaum, Karnataka, India \\ *Corresponding author
}

A B S T R A C T

\begin{tabular}{|l|}
\hline Ke y w o r d s \\
$\begin{array}{l}\text { Surgical site infection, } \\
\text { Triclosan, Triclosan } \\
\text { coated suture, } \\
\text { Antibacterial coated } \\
\text { suture. }\end{array}$ \\
\hline Article Info \\
\hline $\begin{array}{l}\text { Accepted: } \\
\text { 23 October } 2017 \\
\text { Available Online: } \\
\text { 10 December } 2017\end{array}$ \\
\hline
\end{tabular}

\section{Keywords}

Surgical site infection, coated suture,

Antibacterial coated 10 December 2017
Surgical Site infections (SSI) are the most common nosocomial infections, resulting in increased mortality and morbidity in post-surgical patients. It represents an economical burden to healthcare systems. Sutures act as nidus for microorganisms to multiple at the operated site resulting in SSI, thus this study was undertaken to determine the use of antibacterial coated suture to decrease the incidence of SSI in comparison to use of non-coated sutures. Agar Diffusion test (ADT) was used to test the efficacy of antibacterial-coated and non-coated suture material. A good zone of inhibition was seen around the antibiotic coated suture against MRSA, MSSA, Proteus mirabilis, Proteus vulgaris and E. coli and no zone of inhibition against Pseudomonas aeruginosa. Triclosan coated sutures showed good antibacterial activity in-Vitro growth and so may be considered its use as a routine practice.

\section{Introduction}

The term 'surgical site infection' (SSI) was introduced in 1992 to replace the previous term 'surgical wound infection'. ${ }^{1}$ Surgical site infections (SSIs) are defined as infections occurring up to 30 days after surgery (or up to one year after surgery in patients receiving implants) and affecting either the incision or deep tissue at the operation site. ${ }^{2}$

SSI is a common complication comprising a major percentage of health care associated infection (HAI) worldwide. Because of its influence on quality of life, duration of hospital stay, requirement of additional treatment (antibiotics), financial burden; prevention and treatment of SSI is very important task. ${ }^{3}$ Onset of SSI is associated with various factors like malnutrition, DM, implanted foreign materials, type of surgery (clean, clean contaminated or contaminated), including type of suture material used. ${ }^{4,5}$

$66 \%$ of SSI occur at the site of incision as they act as nidus for attachment for organisms as shown in Figure $1 .{ }^{6}$ In view of this many studies have been done to avoid bacterial 
colonization on and around the suture material especially by the use of antibacterialcoated suture material. Even though antibacterial suture material reduces the colonization of bacteria on it, it doesn't kill the bacteria or prevent them from adhering to the suture material once biofilm has been formed making it difficult to treat. ${ }^{7,8,9,10,11}$

The most common organisms responsible for causing SSI are S. aureus-MSSA, MRSA, S. epidermidis, E. coli, Enterococci sp., Proteus sp., Pseudomonas sp., CONS etc.

In this study Triclosan coated suture material is compared with non-coated suture material in-vitro, to know their action on these common organisms causing SSI.

Triclosan was developed in 1960's. It is a broad spectrum antibacterial and antifungal agent found in consumer products like toothpastes, detergents, hand wash antiseptic solutions, soaps, toys etc. 2,4,4'-trichloro-2'hydroxydiphenyl ether is its chemical nature and its possible mode of action being disruption of bacterial cell membrane; which is controversial. ${ }^{12}$ Newer studies have shown that they block the enoyl-acyl carrier protein reductase enzyme (required for bacterial fatty acid synthesis) by targeting Fab I gene. ${ }^{13,14,15}$

\section{Materials and Methods}

This study was carried out in the Department of Microbiology, J.N. Medical College, KLE University, Belgaum.

Agar Diffusion test (ADT) was used to test the efficacy of antibacterial-coated and noncoated suture material.

$0.5 \mathrm{McFarland}$ (which corresponds to $1.5 \mathrm{X}$ $10^{8}$ bacteria per $\mathrm{ml}$ ) standard suspensions were prepared of each organism separately. MRSA, MSSA, E. coli, Pseudomonas aeruginosa, Proteus vulgaris and Proteus mirabilis lawn cultures were made on Muller Hinton Agar (Hi-Media).

$4 \mathrm{~cm}$ each of antibacterial-coated suture material and non-coated suture material were cut with all aseptic precautions and then transferred onto the inoculated MHA plates on each halves.

These plates were then incubated at $37^{\circ} \mathrm{C}$ overnight.

Zone of inhibition were measured perpendicular to mid-point of suture material.

Zone of inhibition around the antibiotic coated suture was compared with that of noncoated suture in millimeters.

\section{Results and Discussion}

After overnight incubation, a good zone of inhibition of $10-11 \mathrm{~mm}$ was seen around the antibiotic coated suture and no zone of inhibition was seen around uncoated suture material against MRSA and MSSA- as seen in Figure 1 and 2.

A zone of $2-4 \mathrm{~mm}$ was seen around the antibiotic coated suture and no zone of inhibition was seen around uncoated suture material against Proteus mirabilis, Proteus vulgaris and E. coli- as seen in Figure 3, 4 and 5 .

And no zone of inhibition was seen against Pseudomonas aeruginosa as in Figure 6. Antibiotic coated sutures inhibited the in-vitro growth of MRSA, MSSA, E. coli, Proteus mirabilis and Proteus vulgaris.

Similar results were found in the study done by Rothenburger's et al., who used triclosan coated polyglactin sutures to look for their action against MSSA, MRSA and S.epidermidis. ${ }^{16}$ 
Fig.1 $11 \mathrm{~mm}$ zone of inhibition seen around the antibacterial coated suture and no zone around non-coated against MRSA

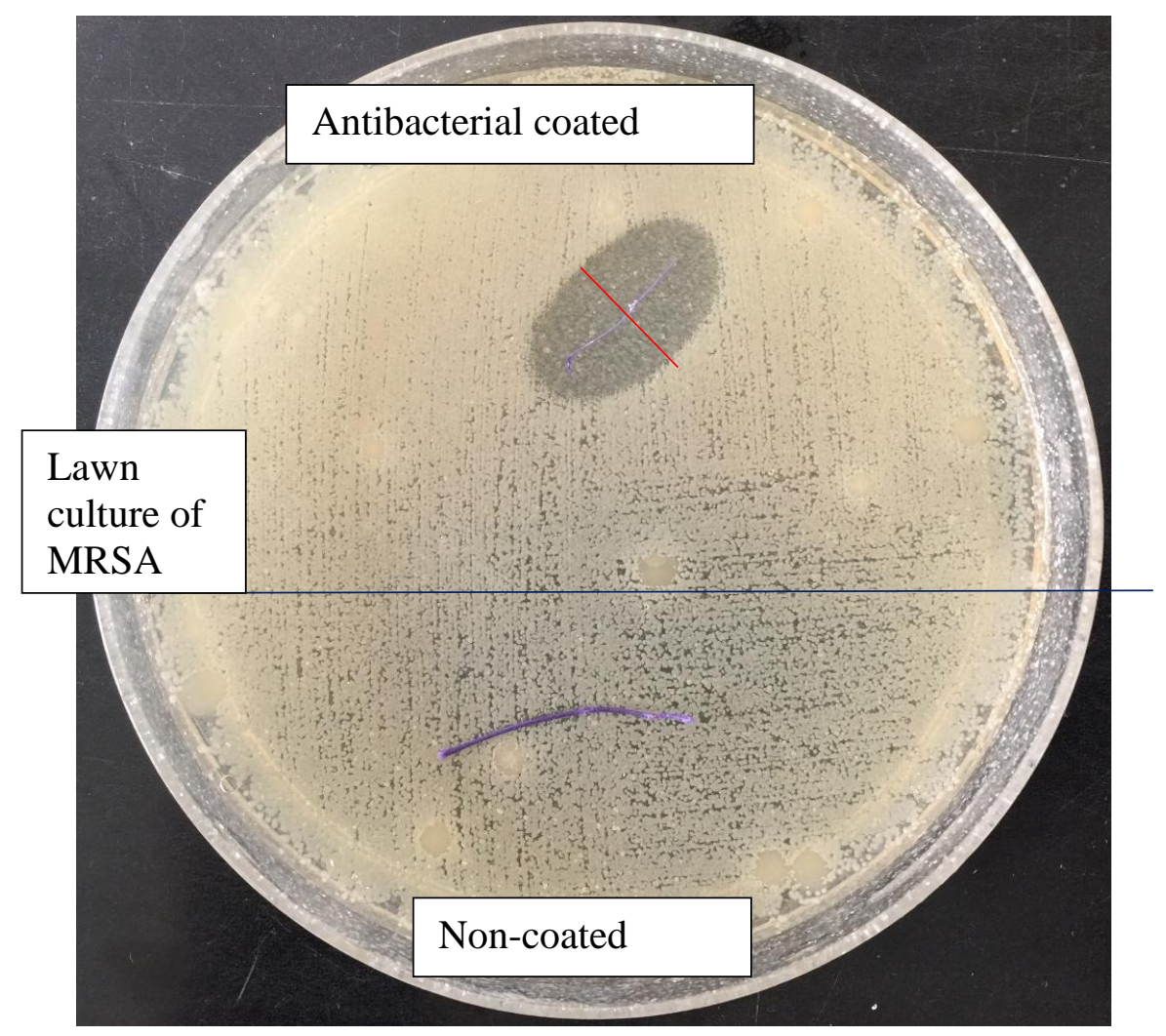

Fig.2 $11 \mathrm{~mm}$ zone of inhibition seen around the antibacterial coated suture and no zone around non-coated against MSSA

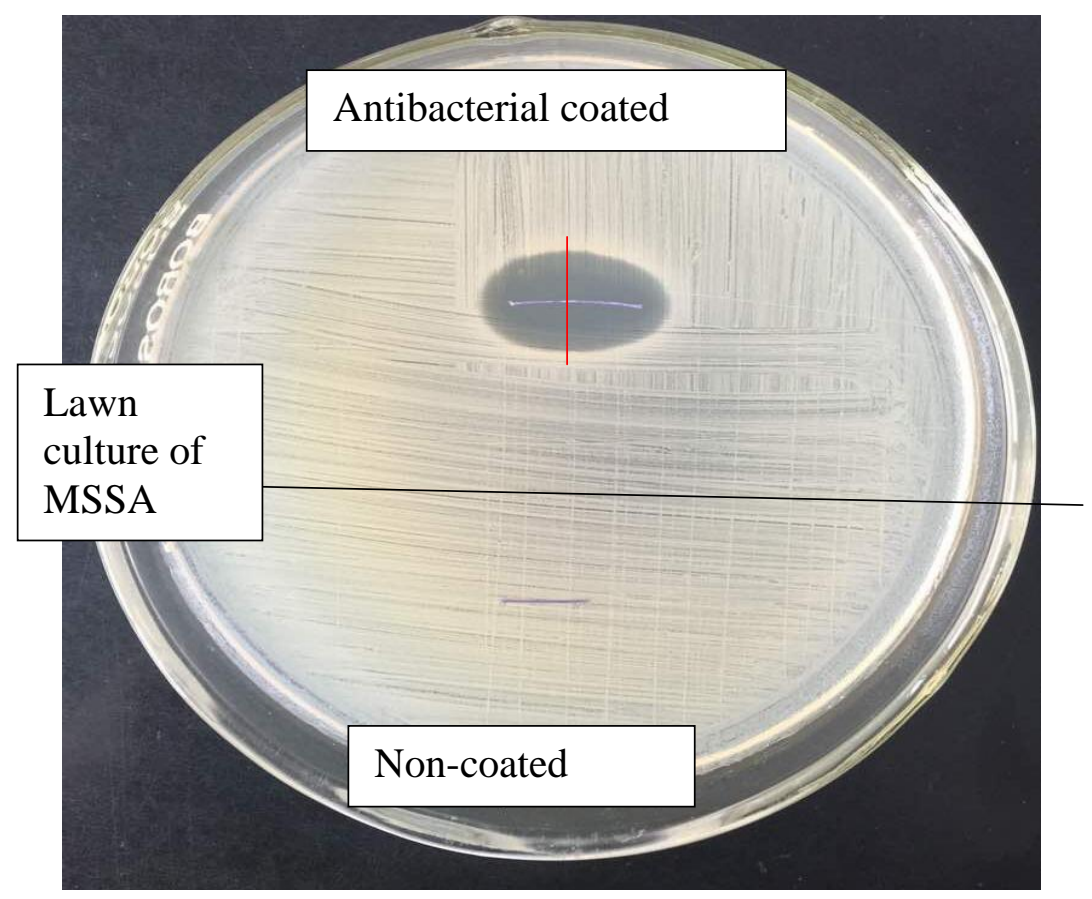


Fig.3 $2 \mathrm{~mm}$ zone of inhibition seen around the antibacterial coated suture and no zone around non-coated against E.coli

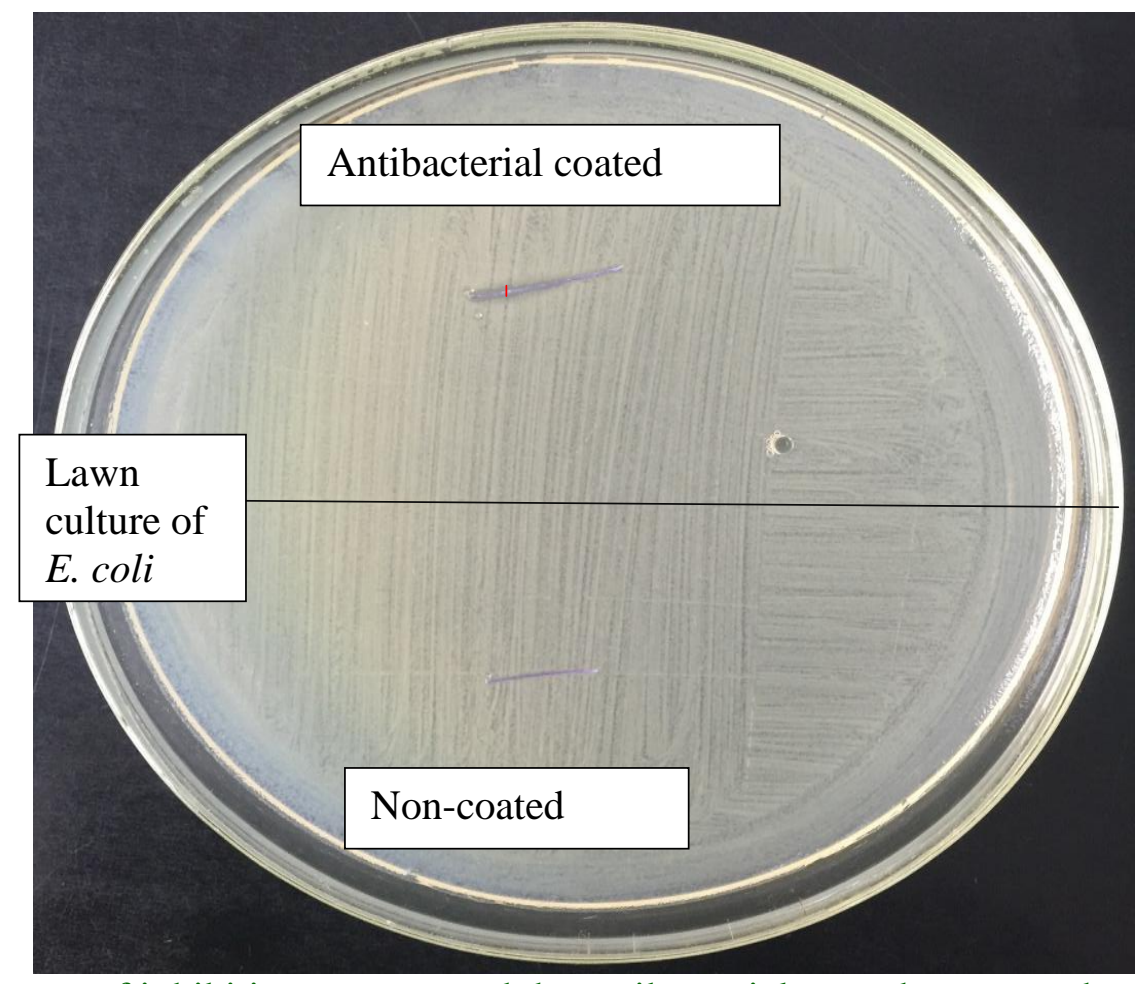

Fig.4 4mm zone of inhibition seen around the antibacterial coated suture and no zone around non-coated against Proteus mirabilis

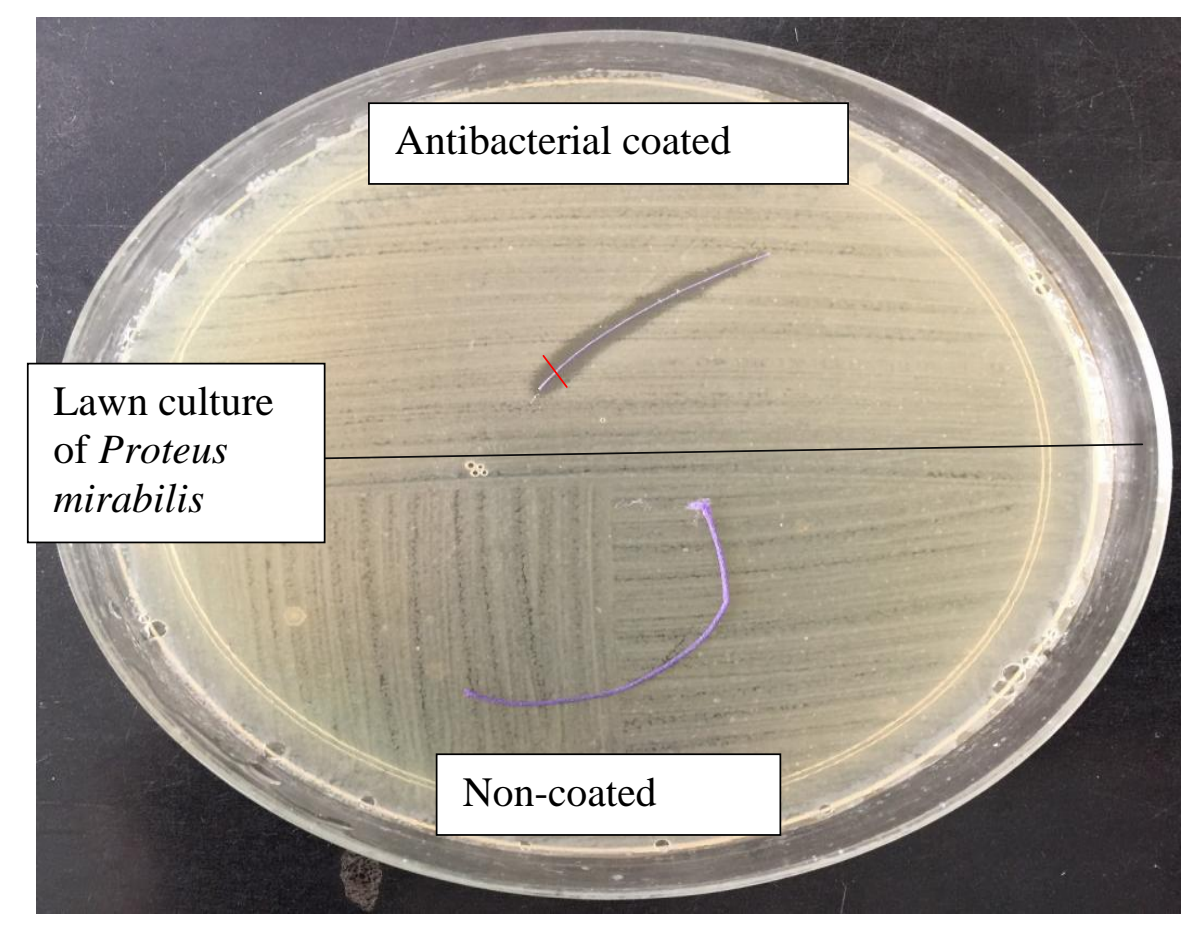


Fig.5 $2 \mathrm{~mm}$ zone of inhibition seen around the antibacterial coated suture and no zone around non-coated against Proteus vulgaris

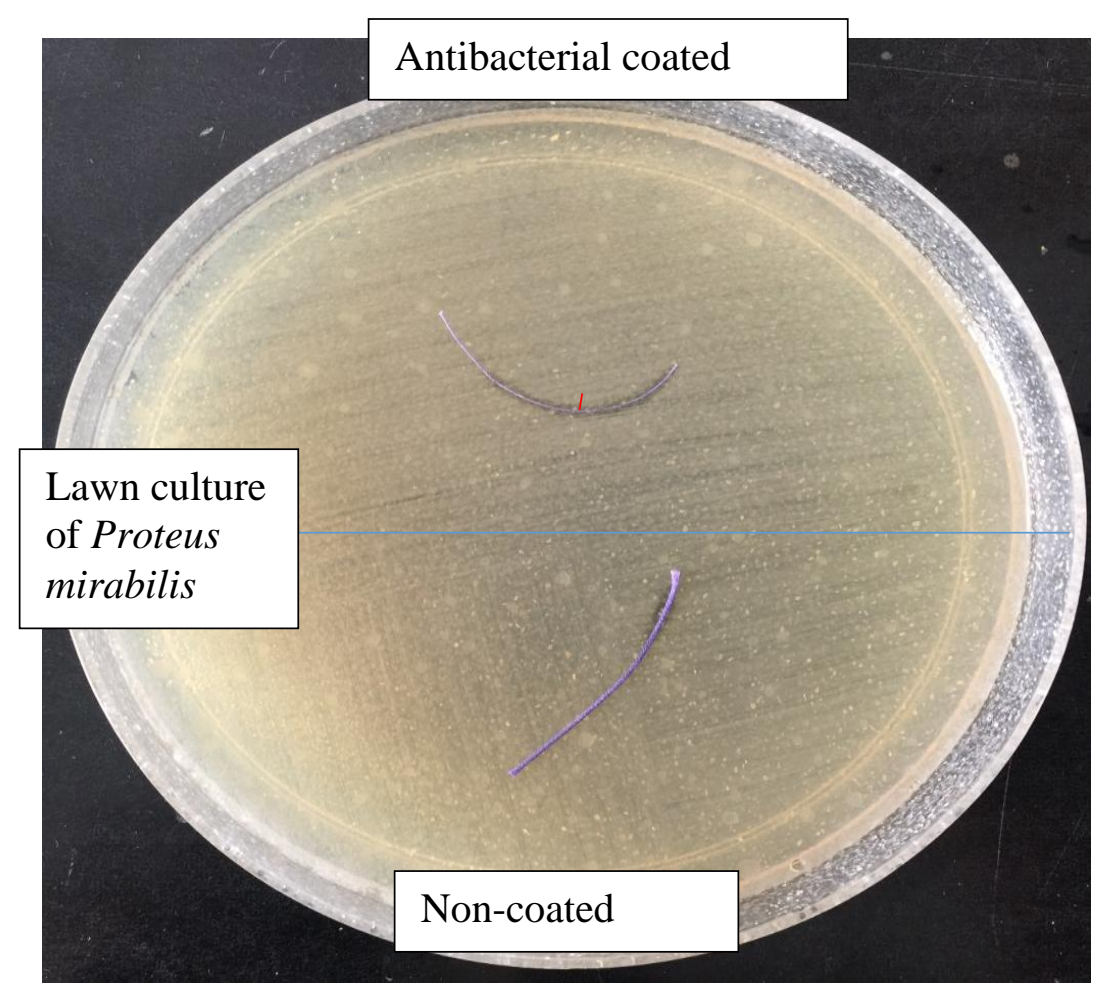

Fig.6 No zone of inhibition seen around both antibacterial coated suture and non-coated against Pseudomonas aeruginosa

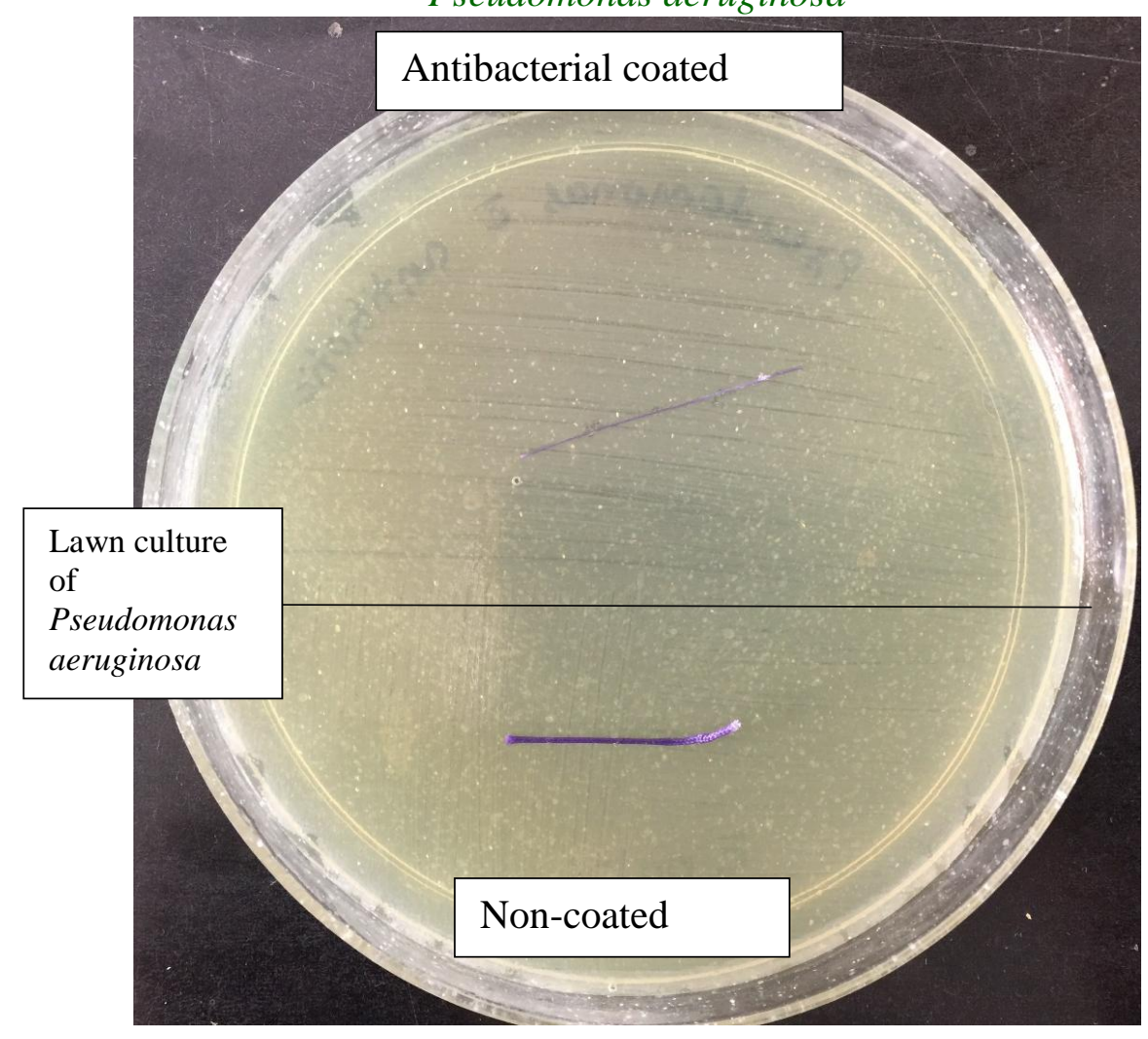


In a study done by Rozzelle et al., infection rate were seen to be reduced by the use of triclosan coated suture for the CSF shunt procedures in comparison to the use of conventional sutures from $21 \%$ to $4.3 \% .^{17}$

Skin is a dynamic home of large number of bacteria, with up to 3 million microorganisms on each square centimeter of skin. ${ }^{18}$ the common skin commensals like CONS, diptheroids etc. were the most common organisms associated with SSI.

Thus it might be assumed that use of antibacterial coated suture could significantly reduce SSI rate and thereby the cost and duration of patient's hospital stay. The antibacterial coated sutures were found effective not only against the common skin commensals causing SSI but also against $E$. coli, MRSA and MSSA too.

In our study Pseudomonas aeruginosa was found to be resistant to both antibacterial coated and non-coated suture. Some of the bacteria such as Pseudomonas aeruginosa and Acinetobacter require high concentration of Triclosan for the bactericidal effect. In the study by Leaper D et al., it was evident that Pseudomonas aeruginosa exhibit innate resistance to Triclosan due to the presence of multi-drug efflux pumps in them that remove Triclosan from cell and also may be due to the presence of varied version of anoyl-acyl carrier protein reductase enzyme (ENR) required for fatty acid synthesis. ${ }^{19}$

The potential benefits of using an antibacterial coated suture may justify the slightly higher cost of these sutures, when compared with cost of managing SSI.

However the results of this in-vitro model must be validated in-vivo prior to its application in humans.
Our study has a limitation of antibacterial suture being not tested against other organisms like Klebsiella pneumonia, Acinetobacter, Strep pyogenes, Staph epidermidis and Enterococcus faecalis, which are known causative pathogens of SSI.

\section{Acknowledgements}

We would like to thank Ethicon (JohnsonJohnson) company for their supply of Triclosan coated suture (VICRYL Plusbraided coated polyglactin 910 violet) and plain non-coated suture material (braided coated polyglactin 910 violet), without whose kind support this project would not have been possible.

\section{References}

1. Donlan RM, Costerton JW. Biofilms: survival mechanisms of clinically relevant microorganisms. J Clin Microbiol Rev. 2002; 15: 167-193.

2. Everett Wg. Suture materials in general surgery. Prog Surg 1970; 8: 14-37.

3. Horan TC, Gaynes RP, Martone WJ, Jarvis WR, Emori TG. CDC definitions of noscomial surgical site infections, 1992: a modification of CDC definitions of surgical wound infections. Infect Control Hosp Epidemiol 1992; 13:606 608 .

4. Howe CW, Marston at. a study on sources of postoperative staphylococcal infection. Surg Gynecol Obstet 1962; 115: 266-275.

5. Leaper D, Assadian O, Hubner NO, McBain A, Barbolt T, Rothenburger S, et al., Antimicrobial sutures and prevention of surgical site infection: assessment of the safety of the antispectic triclosan. Int Wound J. 2011 Dec; 8(6): 556-66.

6. Levy CW, Roujeinikova a, Sedelnikova 
$\mathrm{S}$, et al., Molecular basis of triclosan activity. Nature 1999; 398: 383. http:// dx.doi.org/10.1038/18803.

7. Mangram AJ, Horan TC, Pearson ML, Silver LC, Jarvis WR; Hospital Infection Control Practice Advisory Committee. Guideline for prevention of surgical site infection, 1999. Infect Control Hosp Epidemiol 1999; 20: 247 278.

8. Mangram AJ, Horan TC, Pearson ML, Silver LC, Jarvis WR. Guideline for prevention of surgical site infection. Infect Control Hosp Epidemiol, 1999; 20: $247 \mathrm{e} 78$.

9. Mangram AJ, Horan TC, Pearson ML, Silver LC, Jarvis WR. Guideline for prevention of surgical site infection. Infect Control Hosp Epidemiol, 1999; 27: 97-134.

10. McMurry 1M, Oethinger M, levy SB. triclosan targets lipid synthesis. Nature 1998; 394: 531-532. http://dx.doi. org/10.1038/28970.

11. Montague S, Watson $r$, Herbert $r$. Physiology for Nursing Practice. 3rd ed. New York: Elsevier; 2005.

12. Nucci C, Artini M, Pasmore M, Missiroli F, Costerton JW, Selan L. A microbiological and confocal microscopy study documenting a slime producing Staphylococcus epidermidis isolated from a nylon corneal suture of a patient with antibiotic resistant endophthalmitis. Graefe's Arch Clin Exp Ophthalmol, 2005, 243:951-954.

13. Owens CD, Stoessel K. Surgical site infections: epidemiology, microbiology and prevention. J Hosp Infect. 2008; 70 Suppl 2:3-10.

14. Polous IM, goshchinskii VB, grivenko Sg, Belykh SI, Davydov aB, Bikaliuk IF. The validation of the use of iodinecontaining suture thread in surgical practice. Klin Khir 1993; 1: 49-51.

15. Rothenburger S, Spangler D, Bhende S, Burkley D. In vitro antimicrobial evaluation of Coated Vicryl* Plus antibacterial Suture (coated polyglactin 910 with triclosan) using zone of inhibition assays. Surg Infect (Larchmt) 2002; 3 (Suppl 1): S79-87. http://dx.doi.org/10.1089/sur.2002.3.s179.

16. Rozzelle CJ, Leonardo J, li V. antimicrobial suture wound closure for cerebrospinal fluid shunt surgery: a prospective, double-blinded, randomized controlled trial. JNeurosurg Pediatr 2008; 2: 111-117. http://dx.doi. org/10.3171/PeD/2008/2/8/111.

17. Slater-Radosti C, Van Aller G, Greenwood R, et al., Biochemical and genetic characterization of the action of triclosan on Staphylococcus aureus. J Antimicrob Chemother 2001; 48: 1-6. http://dx.doi.org/10.1093/jac/48.1.1.

18. Ward $\mathrm{KH}$ et al., Mechanism of persistent infection associated with peritoneal implants. J. Med. Micobiol., Vol. 36 (1992), p. 406-413.

19. Zhan C, Miller MR. Excess length of stay, charges, and mortality attributable to medical injuries during hospitalization. JAMA. 2003; 290: 1868-1874.

\section{How to cite this article:}

Soumya, S., Praful S. Maste and Sumati Hogade. 2017. In-vitro Comparison of Antibacterial (Triclosan) Coated Suture Material with Non-coated Suture Material against Common Bacterial Pathogens Causing Surgical Site Infection. Int.J.Curr.Microbiol.App.Sci. 6(12): 3049-3055. doi: https://doi.org/10.20546/ijcmas.2017.612.356 